\title{
Falar na Rádio como Estratégia Política. Retrato etnográfico do racha entre entidades afro-culturais de Ilhéus, Bahia ${ }^{1}$
}

Silvia Garcia Nogueira O baixo custo, a tecnologia de complexidade relativamente manejável por leigos (UEPB) e a intimidade da recepção fazem do rádio um meio universalmente utilizado, possuindo um caráter comunitário (Bordenave 1988: 73-74). No país, o alcance social desse tipo de veículo de comunicação pode ser percebido pela constatação de que o rádio está presente em mais de $90 \%$ dos lares brasileiros (Moreira 2002: 9). Mesmo assim, tem sido pouco explorado como objeto de investigação, em especial no que diz respeito aos aspectos relacionados aos papéis que desempenha e aos significados sociais que adquire.

Partindo da premissa defendida por Thompson (1998) de que o relacionamento com a mídia é uma marca da interação moderna entre os indivíduos, nos períodos de julho a dezembro de 2000 e fevereiro a julho de 2002 realizei uma pesquisa de campo em llhéus (Sul da Bahia) a respeito dos meios de comunicação locais, em particular das cinco emissoras de rádio existentes no município. O produto desse estudo resultou em minha tese de doutorado (Nogueira 2005), que procurou explorar as diversas facetas do rádio - como meio profissional e inserido em uma dimensão social mais ampla - em uma perspectiva etnográfica.

Ao lado de uma análise sobre o relacionamento das rádios com os poderes políticos municipais instituídos e com a esfera religiosa, a tese procurou ainda explorar analiticamente as relações que se estabelecem entre radialistas/ rádios e ouvintes/freqüentadores das emissoras. Entre esses interlocutores, a visibilidade é tida como uma importante moeda de negociação, tornando-se uma estratégia adotada por diversos agentes sociais para alcançarem os mais distintos objetivos.

Foi nesse contexto que, em 2002, atravessando a pesquisa sobre rádio, pude acompanhar a ocorrência de um racha entre entidades afro-culturais de Ilhéus que, a partir de determindado momento, passaram a dialogar em grande medida por intemédio dos meios de comunicação. $O$ recurso à imprensa por parte de representantes de algumas dessas entidades tornou público o conflito e revelou discursos que correspondiam tanto a resultados mais imediatos quanto a 
intenções menos pontuais. No primeiro caso, exigência de prestação de contas do Conselho de Entidades AfroCulturais de llhéus (CEACl) e disputa de poder pela ocupação do cargo de presidente do conselho. No segundo, construção de uma imagem pública baseada na diferenciação dos blocos afro entre si, ou, em outros termos, em processos de singularização.

Antes de apresentar mais detalhadamente o episódio do racha nas rádios, tema central deste artigo, algumas observações acerca dos blocos afro de llhéus fazem-se necessárias. Em primeiro lugar, é preciso salientar que o que está sendo aqui chamado de "racha" (ruptura) não é de modo algum uma novidade entre os blocos afro do município. De acordo com Goldman (2001: 60), a idéia de segmentação ${ }^{2}$ tanto faz parte da genealogia ${ }^{3}$ dos blocos afro de llhéus quanto integra a percepção deles sobre sua própria história. Como observado pelo autor,

“as rupturas que dão origem aos blocos são atribuídas às brigas entre seus componentes, a maior parte ligada a problemas financeiros e/ou desentendimentos sobre a organização do bloco. Além disso, cada um deles esteve, está - e provavelmente estará - de alguma forma ligado a políticos profissionais que ou participaram de sua fundação, ou se aproximaram posteriormente, ou o fazem próximo às eleições" (idem: 59).

Uma segunda observação diz respeito aos modos como os blocos afro de llhéus agenciam suas formas de subjetivação, tendo como referências os desejos simultâneos de diferir e de inclusão social (Silva 2004: 352, 364, 370). Segundo Silva, o desejo de diferir relaciona-se a um "modo de existência negro" (: 370); o de ser incluído está ligado à idéia da realização de um "trabalho social" ou "trabalho comunitário", por sua vez relacionado a uma "concepção ampla de cidadania" - que a partir dos anos 90 "se impôs como uma forma de estar no mundo que todos deveriam 'praticar'" (: 372). Para a autora, se a produção de uma forma de subjetivação é o que singulariza um bloco afro, a homogenização das atividades transformadas em trabalho (artístico ou social) é resultado do processo de "captura" pela "subjetividade capitalística"4 (: 420). Foi diante desse quadro que em 2000 o Dilazenze - bloco que serve de principal referência neste trabalho, mas também nos de Goldman e Silva - criou o Projeto Batukerê, direcionado a crianças e adolescentes na chamada "situação de risco social".

Por fim, uma última observação: a distribuição de recursos públicos pela prefeitura municipal para os blocos afro poderem se apresentar no carnaval e uma frágil, inconstante, contribuição para a manutenção do Batukerê são algumas das estratégias políticas adotadas em que é possível perceber de modo imediato esses processos de inclusão, ou de "captura". Do mesmo modo, com semelhante estratégia de distribuição de recursos financeiros por meio de compra de espaços publicitários ou programas, a prefeitura constrói sua relação com as rádios e os radialistas locais. Seja no caso dos blocos afro-culturais ou das emissoras, essa distribuição é diferenciada, o que gera disputas pelas verbas municipais (talvez, também, movimentaos de segmentação), mas é também o que os "inclui" - rádios e blocos.

Perpassando toda essa discussão sobre formas de singularização e de inclusão, uma noção parece primordial: a de visibilidade. Para mostrar-se diferente ou igual frente ao desejo de inclusão, é necessário antes de mais nada "ser visto". Aí reside justamente o ponto de contato com a pesquisa sobre os veículos de comunicação, na medida em que eles constituem o local por excelência - obviamente não a única forma - para se conseguir visibilidade. Foi nesse contexto que, como dito acima, mesmo sem que tais questões relacionadas diretamente ao assunto fossem o foco da investigação, pude acompanhar de perto alguns dos agenciamentos 
e das estratégias de construção de subjetivação de blocos afro, nos recintos das rádios, na ocasião do racha das entidades afro-culturais de Ilheús. Este artigo pretende, portanto, fornecer uma breve descrição analítica do evento ocorrido - uma espécie de retrato etnográfico - e dos papéis da rádio naquele contexto, tendo como cenário, e matéria-prima, os acontecimentos que se desenvolveram nas emissoras locais.

$$
* * *
$$

Mesmo sem constituir um tema central na pesquisa que empreendi em llhéus sobre as emissoras locais de rádio, uma pergunta que sempre esteve presente foi o motivo pelo qual as pessoas recorrem aos veículos de comunicação. Muitas teorias foram desenvolvidas para responder a essa questão: solidão (Mendelsohn 1979), necessidade de companhia (Avery e Ellis 1979), necessidade de estar informado (Schramm 1979), tema para conversas como meio de socialização em grupos (Dominick 1979). Sánchez-Jankowski (1994) e Canclini (1996) introduzem uma dimensão de cálculo, entendido como estratégia política utilizada por segmentos sociais nas suas relações com a imprensa. Tal estratégia inclui o domínio da linguagem própria ao meio jornalístico e a percepção da dinâmica específica dos profissionais dos meios de comunicação. Para os agentes sociais que a utilizam, trata-se de conhecimentos tidos como úteis para a obtenção dos resultados desejados.

Em Ilhéus, recorrer às rádios - em particular às emissoras $\mathrm{AM}$ - geralmente é uma ação empreendida, individualmente ou por representantes de uma coletividade, como último recurso para serem ouvidos e terem seus pedidos atendidos. Quase todos os que chegam aos recintos das AMs introduzem a explicação sobre o motivo da procura aos meios de comunicação informando já terem passado antes em uma secretaria municipal, em um órgão público, em uma companhia privada, na delegacia ou na justiça, alegando que não tiveram seus problemas resolvidos, ou até mesmo que, no próprio local, foram orientados a procurar a emissora ou um determinado locutor.

Como já foi apontado por Canclini (1996: 26), "desiludido com as burocracias estatais, partidárias e sindicais, o público recorre à rádio e à televisão para conseguir o que as instituições cidadãs não proporcionam: serviços, justiça, reparações, ou simples atenção". Quando se sabe, como é o caso, que a assessoria de comunicação social da Prefeitura possui uma equipe que acompanha diariamente toda a programação de rádio produzida, e que das três emissoras AM, uma é identificada como a "rádio do prefeito", e as demais têm como principal anunciante o poder municipal (Nogueira 2004; 2005), a dimensão estratégica de se procurar a rádio é potencializada pelo conhecimento prévio dessas circunstâncias. Assim, do ponto de vista dos agentes sociais, há uma representação de que se antes eles não haviam sido escutados, a divulgação pública do que os aflige fará com que o sejam. 0 diálogo com os poderes municipais constituídos ocorre, desse modo, por intermédio dos meios de comunicação, particularmente pelas emissoras de rádio, que seriam ao mesmo tempo ouvido e voz de seus interlocutores.

Foi partindo dessa percepção que, no primeiro semestre de 2002, representantes de alguns blocos afro locais procuraram os meios de comunicação para "denunciar" o que consideravam irregularidades da administração do Conselho de Entidades Afro-Culturais de llhéus (CEACl). Ao "tornar pública" a questão, a intenção foi tanto a resolução de um problema factual (a prestação de contas de uma verba recebida da Prefeitura) quanto 
a explicitação de uma disputa política pelo controle do Conselho. Sustentando todos os discursos envolvidos no episódio, porém, a busca pelo que os agentes chamaram de "visibilidade" relacionou-se a uma outra dimensão, que correspondeu à construção do modo como desejavam ser "vistos". Isso foi particularmente significativo no que se referiu a um dos blocos afro envolvidos no episódio, o Dilazenze.

Em decorrência disso, o domínio de determinados códigos próprios aos meios de comunicação, e sua utilização com maior ou menor intensidade, foi encarado por membros desse grupo como um instrumento de persuasão importante para a formação de uma imagem coletiva sobre quem são e o que fazem - ou do quanto o Dilazenze seria diferente dos outros grupos semelhantes que existem na cidade, seja em situações episódicas, seja no dia-a-dia de suas atividades. Pode-se dizer, então, que independentemente dos acontecimentos cotidianos ou extraordinários, a busca da "visibilidade" foi também uma estratégia de gestão de sua subjetividade coletiva como bloco afro, correspondendo a um movimento de desenvolver-se a si mesmo (Deleuze 2001: 93).

O interesse permanente no que foi chamado de "opinião pública" foi justificado pelos membros do Dilazenze em função da importância atribuída à construção de uma visão acerca do bloco por meio da imprensa - visão esta ligada ao que consideraram uma preocupação exclusiva no contexto dos blocos afro de llhéus, a saber, sua "responsabilidade social". Foi justamente na interface entre o que eles diziam que eram, o que queriam que todos soubessem que eles eram e o que achavam que os outros blocos afro deveriam ser que o Dilazenze procurou divulgar, nos meios de comunicação locais, seus posicionamentos morais e políticos, suas atividades e outras informações que acreditavam ser relevantes.

Em outros termos, por ocasião da publicidade do episódio aqui em questão, as relações entre o Dilazenze e as rádios locais colocaram em jogo a própria concepção do que deveria ser a atuação de um bloco afro naquele universo social, segundo a representação nativa de um grupo que se dizia "diferente dos outros".

$* * *$

Naquele dia, no segundo trimestre de 2002, perto do meio-dia ${ }^{5}$, o recepcionista de uma das cinco emissoras de rádio existentes em llhéus, onde eu fazia trabalho de campo, veio avisar que "tem um pessoal do movimento negro aí". Eram dois amigos, acompanhados de mais uma pessoa, todos, de fato, membros de blocos afro locais.

No horário, quem estava excepcionalmente no comando do programa jornalístico das 12 às 13 horas era um locutor - e também operador - de um programa caipira, que ia ao ar entre as 4 e as 7 da manhã. O locutor habitual do horário, que acumulava a assessoria de imprensa de um vereador e era identificado com o grupo político do prefeito, não fora trabalhar. O substituto foi escalado logo depois de ter encerrado seu programa habitual.

Esse locutor chamou meus amigos para o estúdio e perguntou sobre o motivo de estarem procurando a rádio. Um deles contou, então, que o atual presidente do CEACI não teria prestado contas de sua administração e que se suspeitava que havia alguma irregularidade. Disse ainda que ele, presidente do Grupo Cultural Dilazenze, seu irmão, vice-presidente do Dilazenze e do próprio $\mathrm{CEACl}$, e o presidente de outro bloco, o Rastafiry ${ }^{6}$, gostariam de obter esclarecimentos públicos por parte do presidente do Conselho, uma vez que já haviam cobrado a prestação de contas inúmeras vezes sem serem atendidos. 
No ar, repetiram detalhadamente o que já haviam narrado, enfatizando alguns pontos e detalhando outros, cobrando publicamente do presidente do $\mathrm{CEACl}$ uma posição a respeito do assunto. $O$ radialista, como se costuma dizer em jargão típico de rádio, "abriu o microfone" para eles.

Na saída, perguntei a um deles se havia gostado da entrevista. Ele respondeu que sim, avaliando que fora melhor do que a que dera mais cedo na emissora vizinha, identificada como a "rádio do prefeito":

"Antônio Maria7 [apresentador de um programa] ficou me cortando toda hora, meio direcionando o que eu estava dizendo. Lá, antes de entrar no ar, nem disse direito sobre o que era, disse apenas que era sobre o Dilazenze e os blocos afro. Aqui, demos sorte. Se fosse o Mathias Rezende [locutor do horário] não conseguiríamos dizer nada do que gostaríamos".

De acordo com meus amigos, tudo começara por ocasião da entrega do Primeiro Troféu CEACl de Cultura Negra, em abril de 2002, quando eles e outros representantes de blocos afro só foram avisados da cerimônia "na noite anterior" à entrega do troféu. Para promover o evento, a Prefeitura teria repassado cerca de $\mathrm{R} \$ 3$ mil para o Conselho. Questionando esse e outros repasses de dinheiro, o Dilazenze fez uma "denúncia" ao Conselho Fiscal - segundo eles, somente um dos conselheiros teve interesse em apurar os fatos - e, em assembléia, junto com mais quatro entidades, pediu a prestação de contas.

O presidente do CEACl solicitara, então, um prazo de dez dias para isso; tendo o prazo se esgotado, o Dilazenze "partiu para tornar a coisa pública", como disse um representante do bloco. Segundo ele, "mesmo sabendo que poderia trazer uma imagem ruim para o movimento como um todo - 'eles estão brigando por dinheiro' -, poderia também ter um ponto positivo, 'mostrar que nem todos agem assim'".

Resolveram, então, procurar os meios de comunicação. O primeiro deles foi um semanário, por motivos que remetem ao perfil de oposição do jornal, ao fato de ser o mais lido e à boa relação com um dos seus jornalistas, de acordo com a avaliação do Dilazenze. A Região deu destaque ao assunto mas, além do depoimento do grupo que fazia a denúncia, apresentou também uma versão do presidente do $\mathrm{CEACl}^{8}$. Esta dizia que tinha até o final do ano para prestar contas e que o presidente do Dilazenze, que havia presidido o Conselho por muito tempo, nunca teria prestado contas de sua gestão. A partir daí, os representantes do Dilazenze, em suas palavras, "intensificaram os trabalhos":

“fomos ao programa de João Guimarães e Francisco Neves, que tem boa audiência. Isso deu mais impacto que no jornal. Fomos chamados na Prefeitura ${ }^{9}$, porque eram verbas públicas; recebi ameaça por telefone de uma pessoa ligada ao presidente do $\mathrm{CEACl}$. Nossa idéia era provocar esse rebuliço. Depois disso tudo foi convocada uma assembléia. Primeiro, foi escolhido o conselho que comandaria o Memorial da Cultura Negra de llhéus, com a indicação do meu nome para a administração. Depois, eu fiz a denúncia novamente: recursos dos eventos promovidos pelas entidades não tinha; recursos do carnaval não tinha. No final, o presidente do $\mathrm{CEACl}$ apareceu com as notas fiscais e os recursos. Reivindiquei, então, o repasse a que o Dilazenze tinha direito e os outros também fizeram o mesmo. No dia seguinte, menos um ou dois porque o dinheiro acabou, todo mundo recebeu. $\mathrm{Na}$ Assembléia, o presidente do Conselho chegou a admitir que gastara o dinheiro porque a filha estava doente". 
Este episódio não é único: somou-se a outros em que presidentes de associações de moradores, representantes de classes profissionais e outras pessoas recorreram às rádios a fim de fazer "apelos", "denúncias" ou "pedidos". Todos retratam a ida de pessoas aos meios locais de comunicação como último recurso para terem seus pleitos atendidos.

Dominando alguns códigos específicos que permitem o acesso ao universo dos veículos de comunicação, esses agentes sociais costumam apresentar seus problemas já submetidos a uma das rubricas que definem o tipo de assunto a ser abordado. Essas classificações dos temas pelos radialistas - incorporados pelos diferentes atores sociais - definem os propósitos e os destinos dos assuntos por eles trazidos.

Assim, "apelo", de modo geral, corresponde a um pedido de auxílio de qualquer natureza, cujo atendimento depende de terceiros. Pode ser tanto um apelo às autoridades para que a limpeza urbana seja feita em um rua específica, quanto um apelo por apoio emocional. Quase sempre indica que o agente já tentou, sem sucesso, solucionar o problema recorrendo a outros meios. O recurso ao radialista ou à rádio torna-se, assim, uma espécie de chamamento público a fim de ter seu pedido atendido.

"Denúncia", por sua vez, corresponde geralmente à revelação de uma situação tida como errada ou à acusação contra uma pessoa vista como ruim ou prejudicial a alguém - tudo, é claro, de acordo com o padrão de percepção de quem está fazendo a denúncia.

"Pedido", enfim, é um dos principais motivos pelos quais se procura as emissoras de rádio. Corresponde, em grande parte, a solicitações materiais, que podem incluir a doação de cestas básicas, a obtenção de muletas, a oferta de empregos, ou passagens de ônibus para voltar para casa. $\mathrm{O}$ "pedido" é sempre acompanhado de algum drama pessoal que para ele serve de justificativa.

No caso dos blocos afro, a "denúncia" - incluindo a apresentação do motivo para procurar a emissora - constituía uma das principais estratégias utilizadas para colocar em xeque a idoneidade do grupo ligado ao presidente do CEACl. "Fazer pressão", como disse o representante do Dilazenze, tinha como objetivo mais imediato obter as informações contábeis solicitadas. Além disso, também estava em jogo uma disputa política pelo controle do Conselho. No entanto, atravessando a busca pelo alcance tanto de metas mais imediatas (a prestação de contas) quanto de médio prazo (a disputa política), a ferramenta para a obtenção desses resultados era o que o representante do Dilazenze chamou de "visibilidade" - que pode ser entendida tanto como meio para uma ação quanto como um fim em si mesmo.

“Ter visibilidade", para ele, era uma estratégia fundamental para "tornar público" o que estava acontecendo. Cada movimento foi pensado e discutido por seus integrantes: o momento de ir à imprensa, os veículos que seriam utilizados, os horários nas emissoras de rádio, o modo como introduziriam o assunto a ser falado no ar ou nos bastidores. Os critérios utilizados foram desde o conhecimento prévio ou intimidade maior com um jornalista ou radialista até uma avaliação particular de que veículo ou horário teria maior audiência. A ligação política ou não com a Prefeitura e o cálculo de que seriam bem recebidos também foram levados em consideração.

A percepção dos membros do grupo de que o caso realmente tornara-se público foi o "comentário geral na cidade". Segundo o presidente do Dilazenze, as pessoas os paravam na rua para emitir opiniões e pedir detalhes dos acontecimentos. O prefeito os chamou a seu gabinete para discutir o assunto, uma vez que o CEACI recebia verbas públicas e deveria dar esclarecimentos sobre seus gastos. 
Neste caso, pode-se dizer que, em certo nível, o acesso à "visibilidade" por intermédio dos meios de comunicação social engendrou a possibilidade de obtenção de resultados concretos, seja a prestação de contas do $\mathrm{CEACl}$, seja o diálogo direto com a Prefeitura sobre as verbas públicas - ou ainda a tentativa de enfraquecimento político do presidente do $\mathrm{CEACl}$ junto às entidades que compõem o Conselho. Tratou-se, portanto, de uma estratégia utilizada calculadamente para a obtenção de determinados fins, relativamente imediatos, precisos e episódicos.

Além disso, entretanto, ultrapassando as fronteiras do episódio aqui em questão e referindo-se a um outro conjunto de significações, colocou-se em jogo um outro aspecto relacionado à idéia de "visibilidade": não basta ser visto; é preciso ser visto de determinado modo. Para isso, seria necessário mobilizar o máximo de recursos disponíveis, a fim de alcançar o que Goffman (1975: 114-115) chamou de "controle de impressões": tons de voz, escolha de palavras, utilização do termo "denúncia" (jargão tipicamente jornalístico) para apresentar o assunto junto aos profissionais dos meios de comunicação, o roteiro da ordem de exposição dos acontecimentos. Evidentemente, para cada veículo os recursos utilizados foram modificados.

Nesse sentido, os denunciantes pretendiam que o caso fosse "visto" e comentado pelo maior número possível de pessoas - e, nesse contexto, ser visto só poderia significar ser comentado. A esse desejo de ampliação da discussão do assunto para além dos limites das entidades afro locais, porém, correspondia a idéia de que tanto o tema apresentado quanto os envolvidos nos acontecimentos deveriam ser interpretados de modo singular. Assim, os conteúdos veiculados e a identificação dos agentes a eles relacionados pelos receptores das mensagens eram entendidos pelo grupo denunciante como importante ferramenta para a construção de uma imagem de quem seriam, de um lado, as entidades que eram contra as irregularidades e, de outro, as que eram coniventes ou omissas.

Entendendo que o recurso aos meios de comunicação era uma estratégia importante para fazer valer a visão dos acontecimentos daquele grupo de pessoas em particular, os representantes do Dilazenze e dos demais grupos que os apoiaram anexaram às disputas no interior do CEACl uma dimensão simbólica. Ao fazerem isso, explicitaram uma concepção de política como luta simbólica em que os atores procuram monopolizar a palavra pública para fazer valer sua visão de mundo, tida por eles como a mais justa e verdadeira (ver Champagne 1990).

Ter alcançado, para o caso, a "visibilidade" que os envolvidos achavam que deveriam obter, significou, portanto, em um primeiro momento, uma oportunidade de diferenciação entre o conjunto dos blocos afro que questionavam o $\mathrm{CEACI}$ (Dilazenze, Rastafiry e mais dois blocos) dos outros onze que apoiavam a administração do presidente do Conselho.

A partir desse primeiro movimento de diferenciação, contudo, o Dilazenze, em particular, promoveu um segundo movimento, ao dar continuidade à estratégia de apresentar-se como distinto de todos os demais blocos afro da cidade, incluindo os aliados no episódio da denúncia. Segundo o presidente do Dilazenze, "além de não concordarmos com as irregularidades, também não estamos preocupados somente em receber as verbas públicas: o Dilazenze é diferente!".

Esse processo particular de construção pública por meio da imprensa de quem seria o Dilazenze-e, claro, de quem não seria o Dilazenze - não se limitou ao episódio aqui enfocado. Este foi um evento específico, mas o fato é que a entidade e seu presidente vinham procurando fazer uso dos meios de comunicação para mostrar 
sua "diferença", promover seus eventos e divulgar informações que acreditavam importantes para a construção de uma percepção mais generalizada sobre o grupo e suas atividades.

De acordo com o presidente do Dilazenze, a utilização regular dos meios de comunicação, e do rádio em primeiro lugar, vinha fazendo com que os ilheenses passassem a encarar o grupo de modo distinto: não apenas como um bloco afro que só sai no carnaval, mas como um grupo que "promove eventos sociais e é evoluído em outras discussões".

Entre os eventos promovidos e as discussões nas quais estaria envolvido, encontrava-se a realização do projeto Batukerê ${ }^{10}$, que exprimiria justamente uma auto-concepção de que a "responsabilidade social" seria um elemento central na construção pública de quem é o Dilazenze. O grupo disse fazer questão de "mostrar nosso trabalho social", deixando claro que sua preocupação se estende até mesmo às famílias dos alunos que freqüentam o projeto para acompanhar aulas de percussão, dança, artesanato e capoeira - assim como para compartilhar a merenda aí servida.

A idéia de "trabalho social" operou como forte argumento de diferenciação em relação aos outros blocos e serviu como justificativa retórica e discursiva, no episódio citado, para a propalada independência do Dilazenze em relação aos recursos da Prefeitura, bem como à afirmação de que, por isso mesmo, o bloco seria "mais do que um bloco que só sai no carnaval". Além disso, serviu também como argumento para tentativas de captação de recursos de outras fontes e esferas não ligadas à administração municipal.

Foi precisamente na busca da construção de uma imagem social de quem são eles, de seus valores e práticas cotidianas, que o interesse pelo que classificaram como a formação de uma "opinião pública" sobre si apareceu, para os membros do Dilazenze, como um diferencial em relação aos demais blocos afro locais. A preocupação com uma imagem pública e com o que o público pensaria a respeito do grupo apareceu como um indicador sintomático de que os outros blocos só estariam interessados em benefícios próprios e não em um bem coletivo maior. Por isso mesmo, as outras entidades não dariam a mesma importância à opinião pública, uma vez que só estariam interessadas em obter as verbas que já recebiam, independentemente de sua atuação fora do tempo do carnaval.

Uma leitura dessa preocupação do Dilazenze, inspirada em Bourdieu (1981) poderia sustentar que o grupo entende que um importante capital de que é possuidor seria constituído por uma combinação de crédito e confiança nele depositada pelo público, combinação que abrangeria tanto avaliações sobre sua competência como bloco afro - e a incompetência, no caso, do presidente do $\mathrm{CEACl}$ - quanto sobre o que poderia ser entendido como a moral do grupo, suas preocupações sociais que iriam além de meros interesses financeiros.

No episódio aqui em questão, o Dilazenze e seus aliados construíram seus discursos por meio da imprensa tendo como referência o que poderia ser publicamente lido como um posicionamento "ético", ao denunciar irregularidades, contrapondo-se, assim, a uma conduta tida como "suspeita" por parte do presidente do CEACl. Sendo assim, no jogo pela disputa simbólica da versão dos fatos, o Dilazenze identificaria publicamente sua ética como baseada em um valor fundamental para o grupo, a "responsabilidade social".

A tentativa de construção de uma imagem do presidente do $\mathrm{CEACl}$ como alguém cuja conduta mereceria reprovação social, ao contrário dos dissidentes que esperavam obter apoio e aprovação ao fazer a denúncia, 
correspondeu a uma estratégia que procurou contabilizar para o grupo o apoio público ao dar "visibilidade" ao caso. Jogando com o fato de que, em geral, as únicas reações às condutas adotadas por agentes sociais são a simples aprovação ou desaprovação, busca-se provocar a segunda, que, como se sabe, funciona sempre como um tipo de sanção.

Além disso, e na medida em que qualquer indivíduo encontra-se envolvido em uma rede de relações pessoais, ser alvo de uma reprovação social coletiva pode exigir uma reorganização da rede no que diz respeito às posições de poder e aos níveis de influência em seu interior - bem como às próprias interações entre os participantes. Desse modo, a exposição pública, por intermédio da "visibilidade" que os meios de comunicação oferecem, é um modo que alguns agentes sociais encontram para provocar um novo arranjo das posições ocupadas na rede.

Tomando, então, como referência o desejo dos membros do Dilazenze em não somente denunciar ações administrativas irregulares, mas, principalmente, em atingir o objetivo de medir forças em uma disputa de poder entre grupos e pessoas em conflito no $\mathrm{CEACl}$, o recurso aos meios de comunicação locais funcionaram como uma importante arma para provocar um abalo nas posições de prestígio no interior do Conselho ${ }^{11}$. Funcionaram, ainda, como modo de apresentação pública dos posicionamentos éticos e morais do grupo, exibidos como diferentes de todos os demais integrantes daquela rede.

O caso analisado é uma expressão concreta de um conjunto de questões que perpassam os usos dos meios de comunicação por diferentes agentes sociais. O modo como estes se relacionam com a mídia e os objetivos pretendidos variam, mas o recurso à visibilidade e à publicização que os veículos de comunicação de massa possibilitam parece ser uma estratégia comum, compartilhada, que marca a interação moderna entre os indivíduos (Thompson 1998).

Nesse sentido, a mídia funcionaria, ao mesmo tempo, como representante e divulgadora da modernidade (Hunter 1994: 20 apud Fonseca 1997), uma vez que, com o advento da mídia escrita, a percepção de um evento e sua publicização foram alteradas (Avritzer 1998: 8). Segundo Thompson, os meios de comunicação social permitiram que ações ou eventos deixassem de ter que ser presenciados para adquirirem um significado público.

A procura dos meios de comunicação - em especial o rádio por suas características de difusão e imediatismo da transmissão - pelo Dilazenze e por outros agentes sociais, inseridos em um campo político específico, é uma ação empreendida dentro do que Thompson (1998: 124) chamou de administração da visibilidade diante dos outros, "um aspecto inevitável da política moderna", que exige um contínuo processo de "tomada de decisões sobre o que, a quem e como se pode tornar público"(:125). Essas tomadas de decisão costumam levar em consideração tanto os benefícios para o grupo que a exposição pública poderá trazer quanto os riscos que a acompanham. Assim, como aponta o autor, a visibilidade criada pelos veículos de comunicação pode se tornar fonte de um novo tipo de fragilidade (:126): a perda de controle da situação e da construção da imagem de si desejada. E, ainda de acordo com Thompson, uma das formas objetivadas dessa perda de controle na imprensa 
é a veiculação de um "escândalo", que revela publicamente uma atividade até então secreta ou dissimulada: "escândalos geralmente pressupõem conjuntos de normas ou expectativas que são transgredidas pelas atividades em questão, e uma vez reveladas, são denunciadas" (:130). O que conta como escândalo, contudo, varia conforme o contexto, de acordo com as normas e expectativas estabelecidas.

Desse modo, mesmo reconhecendo tanto os aspectos positivos (de diferenciação dos demais blocos que "brigam por dinheiro") quanto os negativos ("trazer uma imagem ruim para o movimento como um todo") das denúncias contra a entidade que representa os blocos afro locais, a opção do presidente do Dilazenze acabou sendo transformar os fatos envolvendo o $\mathrm{CEACl}$ em um escândalo - e isso a despeito dos riscos que o próprio Dilazenze corria enquanto integrante do movimento afro-cultural de llhéus.

O escândalo das irregularidades do CEACl pretendia atingir a imagem pública do seu presidente e daqueles a ele ligados. Obter esse efeito significaria atender a uma expectativa de mudança da conjuntura política da qual o Dilazenze, o Conselho e a Prefeitura de llhéus eram importantes elementos:

“Escândalos podem ocorrer em muitas esferas da vida; mas os escândalos que surgem na esfera política, e que hoje têm grande repercussão, são geralmente aqueles ligados a falhas na administração da visibilidade através da mídia. Escândalo é um risco profissional da política na era da visibilidade mediada" (Thompson 1998: 129-130).

Ao detectar uma espécie de falha na administração da visibilidade por parte do presidente do CEACI - não se preocupar em tornar públicas suas atividades como representante das entidades afro-culturais-, o líder do Dilazenze decidiu tornar públicos segredos envolvendo sua administração. Segredos que, uma vez divulgados, ganharam contornos de escândalo. Para recuperar o domínio de sua imagem pública, o presidente do Conselho tratou de readquirir o controle sobre sua própria visibilidade, passando a responder, também pelos meios de comunicação, às acusações contra ele levantadas. $\mathrm{O}$ fato foi transformado em debate de pontos-de-vista e em disputas em torno dos discursos que prevaleceriam junto à opinião pública, gerando ações concretas dos envolvidos no escândalo.

O Dilazenze e os demais representantes de blocos afro que fizeram as denúncias fundaram uma outra entidade, a Associação dos Blocos Afro do Sul e Extremo Sul da Bahia (ABASE). Essa entidade pretendia diferenciar-se política e simbolicamente da instituição representativa existente - em um movimento segmentar, tal como apresentado acima. Mas não saiu do papel. Com a prestação de contas por parte do presidente do CEACl e por ocasião da eleição para a presidência da entidade, porém, ocorreu uma reorganização das forças políticas dentro do próprio movimento. Enquanto o Rastafiry optou por apoiar o presidente candidato à reeleição, o Dilazenze escolheu concorrer com candidato próprio - ato que confirmou a concepção que os membros desse bloco possuem de si mesmos e que procuram projetar para os outros, ou seja, de que se trata de um bloco diferente dos demais em muitos aspectos.

O episódio também gerou uma mudança de conduta da parte do presidente do CEACl: fez uma espécie de mea culpa, admitindo seu erro e ressaltando que o estava corrigindo; prestou contas de sua administração e devolveu o dinheiro para os blocos. Aparentemente, o desfecho do escândalo, com atitudes que deveriam ter sido tomadas desde o início, recolocou a situação em conformidade com as expectativas iniciais, o que ficou visível com a reeleição do presidente do $\mathrm{CEACl}$. 
Como os recursos em questão eram provenientes da Prefeitura, esta, a fim de evitar qualquer envolvimento público com uma situação irregular e malvista, decidiu interromper o repasse de verbas ao $\mathrm{CEACl}$ até que tudo fosse esclarecido. Ao chamar, durante o período do escândalo, os dois lados para conversar em seu gabinete, o prefeito - com interesses políticos particulares - tentou trazer para uma esfera mais restrita as divergências internas ao movimento afro-cultural. Tratava-se, então, de uma tentativa de assumir o controle sobre a visibilidade do caso e sobre seu papel nos acontecimentos.

Ao final do episódio, as rádios e seus profissionais fortaleceram sua imagem de prestadores de um serviço público. Ao "abrirem os microfones" para os diversos segmentos envolvidos no caso e permitirem a manifestação de uma variedade de discursos no ar, as rádios não apenas deram um claro sinal da chamada "democracia dos microfones" (com a participação das entidades afro-culturais), como trouxeram para uma esfera pública a discussão de um assunto que, por princípio, é do interesse da coletividade (o modo como verbas municipais são utilizadas).

Para Souza (2003: 5), o rádio, em particular as emissoras AM, é um lugar onde "a comunidade pode expor suas necessidades, tornar público seus problemas e propor soluções", assumindo, assim, o papel de "organizador" da comunidade. De acordo com Guareschi (2000), o próprio rádio ao se definir inclui necessariamente a comunidade, tornando-se um meio de "mão dupla" (Avery e Ellis 1979: 112). Desse modo, não é tanto a radiodifusão em si mesma que parece relevante. O que mais importa são as relações que estabelece por meio da fala: "essa abertura de fazer do ouvinte também falante, permite ao meio rádio servir de palco para debates em torno dos problemas da comunidade, além de disseminar resultados positivos que sirvam de modelo para as comunidades vizinhas" (Souza 2003: 10).

Na medida em que os microfones são abertos para diversos agentes sociais, que seus direitos de falar e de ser ouvidos são de algum modo garantidos, eles acreditam ter adquirido poder - mesmo que instantâneo, temporário. A procura da rádio como último recurso para a solução de problemas é que define em grande medida o rádio como prestador de um "serviço de utilidade pública", segundo os profissionais do meio.

Por outro lado, o uso dos meios de comunicação, e os efeitos sociais que acarreta - por exemplo, a visibilidade alcançada -, estabelece, de algum modo, uma mudança no status dos agentes na rede de relações na qual estão inseridos. Criam-se novas responsabilidades e modos de interação a partir dos posicionamentos publicamente assumidos. Em parte, isso ocorre não apenas pelo relativo, instantâneo e/ou temporário poder (da palavra, de pressão da opinião pública) adquirido, mas por intermédio de um compromisso estabelecido com esse público e consigo mesmo: no caso do Dilazenze, parecer diferente dos demais, ser diferente dos demais e manter essa diferença.

Desse modo, a utilização dos meios de comunicação e o desejo manifesto de recorrer cada vez mais a eles $^{12}$ - mobilizando a opinião pública a seu favor -, presentes na fala do presidente do Dilazenze, refletem um modo estratégico de construção do grupo como um bloco ético, socialmente responsável e com interesses mais amplos que ultrapassam os exclusivamente financeiros. Além disso, revela um modo singular de agenciamento da subjetividade, com referências tanto a avaliações internas quanto externas ao grupo, que, de algum modo, norteiam as condutas de seus integrantes e, em última instância, avaliam sua razão de ser e existir socialmente. 
Ao pretender tornar visíveis suas ações e práticas cotidianas, bem como seus valores morais e éticos mais preciosos, o Dilazenze tenta apresentar para todos - os membros do próprio grupo, os outros blocos afro e a população em geral - o compromisso assumido com a comunidade no qual está inserido. É justamente pelo discurso da "responsabilidade social", ao envolverem uma coletividade maior, que assuntos e práticas que poderiam ser entendidos como restritos a um universo reduzido - de pessoas sob "risco social"13, afrodescendentes, de uma determinada localidade geográfica específica - são ampliados. Nesse instante, os mecanismos de "captura" revelam-se eficazes e sua condição de "incluído" é reafirmada. 


\section{NOTAS}

1 Este artigo é uma versão modificada e ampliada da comunicação apresentada no Fórum de Pesquisa "Políticas e Subjetividades nos 'Novos Movimentos Culturais'", na 24a Reunião Brasileira de Antropologia, realizada em Olinda (PE), em junho de 2004. Aproveito para agradecer a Marcio Goldman e Miriam Hartung os preciosos comentários realizados na ocasião do Fórum de Pesquisa e, posteriormente, durante a transformação da comunicação oral em artigo.

2 De acordo com Goldman (2001: 84-85), “a própria segmentaridade, ao contrário do que se costuma imaginar, não consiste na divisão de uma suposta unidade primeira em entidades discretas, mas na conversão de multiplicidades em segmentos, ou seja, em unidades simultaneamente divisíveis e unificáveis".

3 Para uma genealogia mais completa dos blocos afro de llhéus ver todo o "Encontro 3" de Silva (2004) e, de modo resumido, Goldman (2001: 59).

4 Ao explicar a idéia de "captura", Goldman (2001: 84) cita Deleuze e Guattari (1980: 531-532), para quem o termo corresponde à "'essência interior', ou [à] 'unidade', de todas as formações estatais [...]; o Estado é capaz até mesmo de imprimir sua forma aos grupos que a ele se opõem ou aos movimentos que dele tentam escapar (Herzfeld 1996: 77)". Já "subjetividade capitalística" corresponde ao que Silva (2004: 351), lembrando Guattari (Guattari e Rolnik 1996: 15), definiu como "o desejo de 'incluir' quem supostamente está 'fora', ou seja, aqueles que estariam exc/uídos do 'sistema' e de seus benefícios".

5 Meio-dia é considerado um "horário nobre" no rádio. A idéia de "horário nobre" se contrapõe à de "horário morto". Enquanto o primeiro refere-se aos horários do dia de maior audiência no rádio (manhã e tarde), o segundo corresponde ao período de pouca audiência (noite). Esta diferença é explicada pela representação compartilhada no meio de que, no período de tempo em que são apresentadas as novelas televisivas, pouca gente ouve rádio.

6 O Dilazenze e o Rastafiry são dois dos três blocos afro considerados "grandes", e dotados de grande prestígio, em Ilhéus.

7 Como nos demais casos presentes neste trabalho, os nomes são fictícios.

8 De acordo com Tuchman (1993: 79-83), apresentar versões conflitantes é um procedimento estratégico desenvolvido pelos jornalistas para alcançar uma aparência de objetividade das notícias.

9 Goldman (2001: 83) chama atenção para o fato de que os distintos segmentos políticos procuram capturar e se articular com segmentos do movimento negro da cidade. Ambos obedeceriam, assim, a uma lógica segmentar.

10 Silva (2004) descreve e discute, em sua tese sobre os movimentos negros de llhéus (Sul da Bahia), questões relativas à criação e às trajetórias do projeto Batukerê. De acordo com a autora, o Batukerê expressa o que é definido como o caráter "social" do Dilazenze, que trabalharia para uma coletividade (: 353).

11 Apesar do abalo causado pela divulgação do caso na imprensa local, em abril de 2004, o presidente do CEACl foi reeleito, com o apoio do Rastafiry. Concorrendo pela ocupação do cargo, contrário à administração vigente, estava o então vice-presidente da entidade, irmão do presidente do Dilazenze.

12 A respeito das relações do Dilazenze com a imprensa, em 2004, o então presidente do grupo - na época diretor do Memorial de Cultura Negra de Ilhéus, nomeado pela prefeitura - dizia ter passado a realizar informativos de divulgação das atividades e dos eventos promovidos pelo Memorial e pelo Dilazenze. Além disso, convidado pelo Diário de /lhéus, passou a escrever uma coluna regular sobre o movimento negro e o Memorial. Finalmente, para o futuro, disse estar estudando a possibilidade de fazer um programa ou participar mais ativamente da programação de rádio, ainda sem saber em que emissora. Percebe-se, desse modo, uma intensificação na utilização dos meios de comunicação pelo grupo ao longo do tempo, contribuindo, segundo seu presidente, para que as pessoas desmistificassem "outros preconceitos em relação aos blocos afro".

13 "Risco social" é uma expressão adotada pelo grupo para se referir, em geral, a pessoas que vivem no limite do que é percebido como uma vida dentro de determinados padrões sociais e morais de dignidade. Os riscos referem-se, portanto, e simultaneamente, tanto a condições de existência materiais (permitindo, por exemplo, seguir uma profissão, ou impedindo a participação em práticas ilegais) quanto simbólicas (orgulho do pertencimento afro-cultural, ver-se como alguém inserido e não excluído de uma coletividade mais ampla). 


\section{REFERÊNCIAS BIBLIOGRÁFICAS}

AVERY, Robert \& Robert Ellis. 1979. “Talk Radio as an Interpersonal Phenomenon”. In Gary Gampert and Robert Cathcart (eds.) Inter/Media, Interpersonal Communication in a Media World. New York: Oxford University Press.

AVRITZER, Leonardo. 1998. "Apresentação". In John B. Thompson, A Mídia e a Modernidade. Uma Teoria Social da Mídia. Petrópolis: Vozes.

BORDENAVE, Juan E. Diaz. 1988. O que é Comunicação Rural. São Paulo: Brasiliense.

BOURDIEU, Pierre. 1981. "La Représentation Politique. Eléments pour une Théorie du Champ Politique". Actes de la Reecherche en Sciences Sociales 36-37:3-24.

CANCLINI, Néstor García. 1996. Consumidores e Cidadãos. Conflitos Multiculturais da Globalização. Rio de Janeiro: Editora UFRJ.

CHAMPAGNE, Patrick. 1990. Faire L'Opinion. Le Nouveau Jeu Politique. Paris: Les Editions de Minuit.

DELEUZE, Gilles. 2001. Empirismo e Subjetividade. Ensaio sobre a Natureza Humana segundo Hume. São Paulo: Ed. 34.

DOMINICK, Joseph. 1979. “The Portable Friend: Peer Group Membership and Radio Usage”. In Gary Gampert and Robert Cathcart (eds.), Inter/Media, Interpersonal Communication in a Media World. New York: Oxford University Press.

FONSECA, Alexandre Brasil. 1997. “Além da Evangelização: Interpretações a Respeito da Presença da Igrejas Evangélicas na Mídia Brasileira". Comunicação \& Política IV(2), nova série: 81-116.

GOFFMAN, Erving. 1975. A Representação do Eu na Vida Cotidiana. Petrópolis: Vozes.

GOLDMAN, Marcio. 2001. "Segmentaridades e Movimentos Negros nas Eleições de llhéus". Mana 7(2):56-93.

GUARESCHI, A. Pedrinho. 1993. "Relações Comunitárias, Relações de Dominação". In Participação é Conquista: Noções de Política Social Participativa. São Paulo: Cortez.

HUNTER, James. 1994. "What is Modernity? Historical Roots and Contemporary Features". In Philip Sampson et al. (ed.), Faith and Modernity. Oxford: Regnun Books.

MENDELSOHN. 1979. "Listening to Radio". In Gary Gampert and Robert Cathcart (ed.) Inter/Media, Interpersonal Communication in a Media World. New York: Oxford University Press.

MOREIRA, Sonia Virgínia. 2002. Rádio em Transição. Tecnologias e Leis nos Estados Unidos e no Brasil. Rio de Janeiro: Mil Palavras.

NOGUEIRA, Silvia Garcia. 2004. “Entre a Religião e a Política: Fazendo Rádio em uma Cidade do Sul da Bahia”. Estudos em Jornalismo e Mídia 1(1): 58-70.

2005. Facetas do Rádio. Uma Etnografia das Emissoras de llhéus (Sul da Bahia). Tese de Doutorado. Rio de Janeiro:

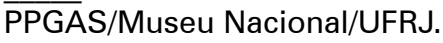

SÁNCHEZ-JANKOWSKI, Martin. 1994. "Le Gangs et la Presse. La Production d'un Mythe National”. Actes de La Recherche en Sciences Sociales 101/102: 101-117.

SCHRAMM, Wilbur. 1979. "Channels and Audiences”. In Gary Gampert and Robert Cathcart (eds.), Inter/Media, Interpersonal 
SILVA, Ana Cláudia Cruz da. 2004. Agenciamentos Coletivos, Territórios Existenciais e Capturas. Uma Etnografia de Movimentos Negros em Ilhéus. Tese de Doutorado. Rio de Janeiro: PPGAS/Museu Nacional/UFRJ.

SOUZA, Alana. 2003. Rádio, um Lugar de Participação. Monografia de conclusão do curso de Comunicação Social, habilitação em Rádio e TV. Ilhéus (BA): Departamento de Letras e Artes, Universidade Estadual de Santa Cruz.

THOMPSON, John B. 1998. A Mídia e a Modernidade. Uma Teoria Social da Mídia. Petrópolis: Vozes.

TUCHMAN, Gaye. 1993. "A Objectividade como Ritual Estratégico: uma análise das noções de objectividade dos jornalistas". Nelson Traquina (org.) Jornalismo: questões, teoria e "estórias". Lisboa: Vega.

WEBER, Max. 1944 [1922]. Economia y Sociedad. Esbozo de Sociologia Comprensiva (I). México: Fondo de Cultura Económica. 
Falar na Rádio como Estratégia Política. Retrato etnográfico do racha entre entidades afro-culturais de Ilhéus, Bahia

\section{RESUMO}

Em 2002 ocorreu um racha entre representantes de entidades que integram o Conselho de Entidades Afro-Culturais de Ilhéus (CEACI) e o grupo do presidente do Conselho. Na ocasião, os dissidentes procuraram os meios de comunicação do município para denunciar a conduta do presidente e fazer pressão para que ele esclarecesse pontos de sua administração. O veículo mais utilizado foi o rádio. "Ir à rádio" faz parte de uma estratégia política utilizada por diversos segmentos sociais. O recurso é empregado geralmente quando outras formas de apelo falharam. Deste modo, este artigo pretende fornecer uma breve descrição analítica do evento ocorrido - uma espécie de retrato etnográfico -, e dos papéis da rádio naquele contexto, tendo como cenário, e matéria-prima, os acontecimentos que se desenvolveram nas emissoras locais.

PALAVRAS-CHAVE: rádio, Ilhéus (Sul da Bahia), movimento afro-cultural.

\section{Talking on the Radio as a Political Strategy. An ethnographical portrait of the schism among afro-cultural groups in Ilhéus, Bahia}

\section{ABSTRACT}

A schism took place in 2004 oposing some of the members of the Conselho de Entidades Afro-Culturais de Ilhéus/Bahia (CEACl) against the group closer to its president. On that occasion, the dissidents resorted to local media in order to denounce the president's behavior and forcing him to clarify some aspects of his administration. For this purpose Radio stations were their number one communication option. "Going to the radio" is part of a political strategy employed by different social segments. In general, this resource is used when others have failed. This article presents a brief analytical description of the dispute mentioned above and of the roles played by broadcasting in that context. - a kind of ethnographical portrait made of the occurrences which took place at the local stations.

KEYWORDS: radio, Ilhéus (Southern Bahia, Brazil), afro-cultural movement. 